\title{
Arrevistamiento en el diseño de primeras planas de un diario generalista español. Las portadas del diario Público
}

\author{
Recibido: 04 de octubre de 2016 \\ Aceptado: 09 de mayo de 2017 \\ Publicado: 27 de noviembre de 2017
}

César Mejía Chiang cmejiac@usmp.pe

Universidad de San Martín de Porres (Perú)

Resumen: El presente artículo detalla las temáticas abordadas, así como la estilística y el lenguaje gráfico desplegado en las portadas de la versión impresa del diario Público (octubre 2007 - junio 2008). Sostenemos que el carácter "arrevistado" de las portadas durante el mencionado período no sólo explotaron una serie de recursos visuales (propios de publicaciones orientadas a una lectoría joven, familiarizada con las nuevas tecnologías portátiles y multimedia), sino que ayudaron a canalizar una sistemática crítica hacia los sectores políticos, aparentemente "conservadores" de España, ensalzándose así la raigambre "progresista" del diario.

Palabras clave: Diseño periodístico, diario Público, portadas, diarios generalistas, prensa española.

\begin{abstract}
This paper details thematic, as well as style and graphic language in Público newspaper's covers (October 2007 - June 2008). We assume that poster design in Público covers, during the cited period, exploited many visual resources (familiar with publications aimed to young readers and users of portable technologies and multimedia) and helped to canalize a systematic critic to "conservative" political sectors in Spain, underlining the "progressive” nature of this newspaper.
\end{abstract}

Key words: Journalistic Design, Público Newspaper, Covers, General Newspapers, Spanish Press. 


\section{Introducción}

Durante su permanencia en el mercado editorial de la prensa española (2007-2012), el diario Público se caracterizó por su propuesta visual, sobre todo en sus portadas, las cuales fueron reconocidas por premios internacionales de diseño periodístico (Público, 2008: 60) desde sus primeras ediciones ${ }^{1}$. Esta vistosidad gráfica estuvo acompañada por una decidida posición "progresista"2 que se mantuvo incólume incluso durante la grave crisis financiera que sufrió el segundo gobierno de Rodríguez Zapatero³, al cual apoyó desde el proceso electoral del 2008.

Este progresismo aparece clarificado desde su primer número. En el suplemento especial "Hoy nace tu diario" (26/IX/2007), Público explica lo siguiente: "Renunciamos a la comodidad de ser neutrales y asumimos los riesgos de defender un modelo complejo de sociedad. Creemos en el progreso más allá de su acepción política"4, lo cual se extendería hacia el campo del diseño periodístico y la propuesta visual del mismo diario. El primer director de esta publicación, Ignacio Escolar (2007), defiende la arrojada propuesta visual del diario al explicar que los "titulares atractivos" y la "puesta en página moderna" no responden a un modelo "amarillista":

"Una cosa es la forma y otra el fondo. Una noticia no es más seria si está escrita en columnas largas y apretadas y en blanco y negro. Queremos ser ágiles y modernos, pero no sensacionalistas ni poco rigurosos".

En el citado suplemento, adjunto al primer número, Público (2007) se define como "un periódico con intención popular y voluntad de ser accesible", con la prioridad de crear un "estilo moderno, próximo y vivo, desde el diseño a la información". Esta vocación por la legibilidad en el mensaje (tanto textual como gráfico) se vertió con mayor claridad en las portadas, elaboradas por el estudio de Toni Cases (quien comandó los procesos de rediseño de los diarios The Independent, El Clarín, Il Corriere Della Sera, El Periódico de Catalunya, entre otros diarios). El formato tabloide (usado ampliamente por la prensa española) nutrió las intenciones de Público de crear un espacio de impacto visual y tipográfico, echando mano de una amplia paleta de colores y de elementos gráficos que sintetizaron y amenizaron la noticia principal.

1. Cabe recordar que en la XVI Edición de los Premios Malofiej, Público fue el diario más premiado, obteniendo seis preseas, sólo superado por el británico The Guardian. Asimismo, la V Edición del Certamen NH y The Society for News Design (SND) le entregaron nueve y cinco galardones respectivamente..

2. Si bien apareció como un diario de corte juvenil, desde sus inicios Público abordó (a través de sus textos opinantes, infografías y reportajes especiales) el debate del laicismo, el multiculturalismo, la libertad sexual, entre otros temas polémicos.

3. La desaparición de Público y de Rodríguez Zapatero de la palestra política no parece ser coincidencia. El primero apareció apenas pocos meses antes del proceso electoral del 2008 y tras algunos años de cierta estabilidad, sufrió los embates del mercado y languideció lentamente hasta suprimir su versión impresa en febrero de 2012, cuando la legislatura del ex líder socialista había llegado a su fin pocos meses antes.

4. En todo caso, este diario remarca su independencia ideológica, sin condicionamientos ni sujeciones externas: "La primera obligación de un periódico es con sus lectores, no con gobiernos, ni partidos ni grupos de poder. Y Público pretende por encima de todo ser reflejo de un periódico independiente, intermediario veraz entre los hechos y los lectores, abiertos desde el primer día a la participación ciudadana. Sin adoctrinamiento, pero con pasión, sin complejos, pero con cerebro" (Público, 2007). 
Los tres siguientes apartados ahondan en las características expuestas en las portadas de Público (tanto en el aspecto visual como en el temático) durante sus tres primeros trimestres. La elección de este período de estudio responde a la importancia que adquirió el diseño gráfico en las primeras páginas de dicho diario, que en ese entonces buscaba posicionarse y consolidarse dentro de un mercado altamente competitivo, liderado por El País, el cual marcaba la pauta precisamente dentro del espectro de la izquierda en la prensa española.

\section{Primer trimestre (octubre - diciembre 2007)}

Las portadas de Público partieron de un esquema modular-horizontal conformado por cuatro bloques cuadrangulares: el primero de estos se ubicó encima de la cabecera, siempre con fondo gris, subdivido en tres cuerpos, cobijando dos noticias y un espacio publicitario o de promoción. Más abajo, el rótulo y el logotipo ocupan el margen derecho y central. Al extremo se halla la información básica del diario: lugar de publicación, fecha y número de edición.

El tercer bloque es el principal: se apostó por los tonos rojizos como fondo para sus titulares, que sólo cedieron ante la presencia de la fotografía principal de la portada. Más allá de intentar armonizar con el color del rótulo, el empleo de un color tan intenso como el rojo pretendió impactar visualmente al lector.

En las figuras 1 y 2 observamos que los titulares se ubicaron en el centro de la página. En el primer caso, para separar convenientemente las fotografías de tres líderes abertzales de un extenso subtítulo explicativo de tres líneas. En la segunda portada, la disposición del titular ("En la frontera") buscó resaltar dos fotografías (a pesar de no estar en altas), las cuales recogieron reacciones opuestas al producirse la visita de los reyes de España a Ceuta y Melilla.

Figuras 1 y 2: Portadas de orientación horizontal.
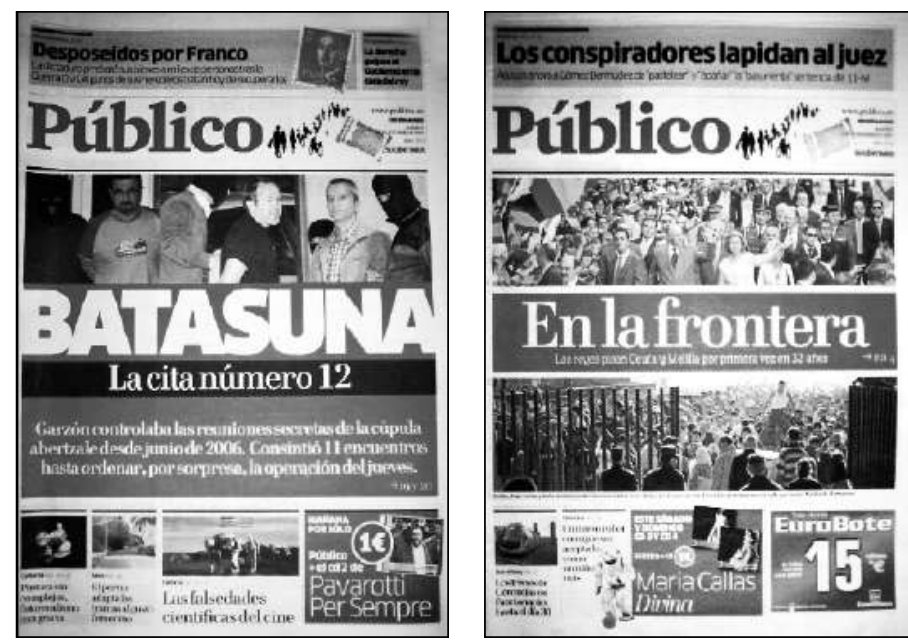

Fuente: Diario Público (6/X/2007 y 6/XI/2007). 
El cuarto bloque suele contener varias informaciones, con sus respectivas fotografías. Sin embargo, algunas portadas suprimieron el bloque inferior con la finalidad de conceder más espacio a los subtítulos de la noticia principal. En la figura 3, el titular fue separado por la foto que muestra a los culpables del atentado terrorista: sus dos segmentos se hallan dentro de recuadros con fondos diferentes, rojo y negro respectivamente. Estamos frente a un titular fragmentado o "multi-titular", ya que la presencia de los puntos suspensivos sugiere un sentido de continuidad en la frase.

Figuras 3 y 4: Portadas con tres bloques cuadrangulares.
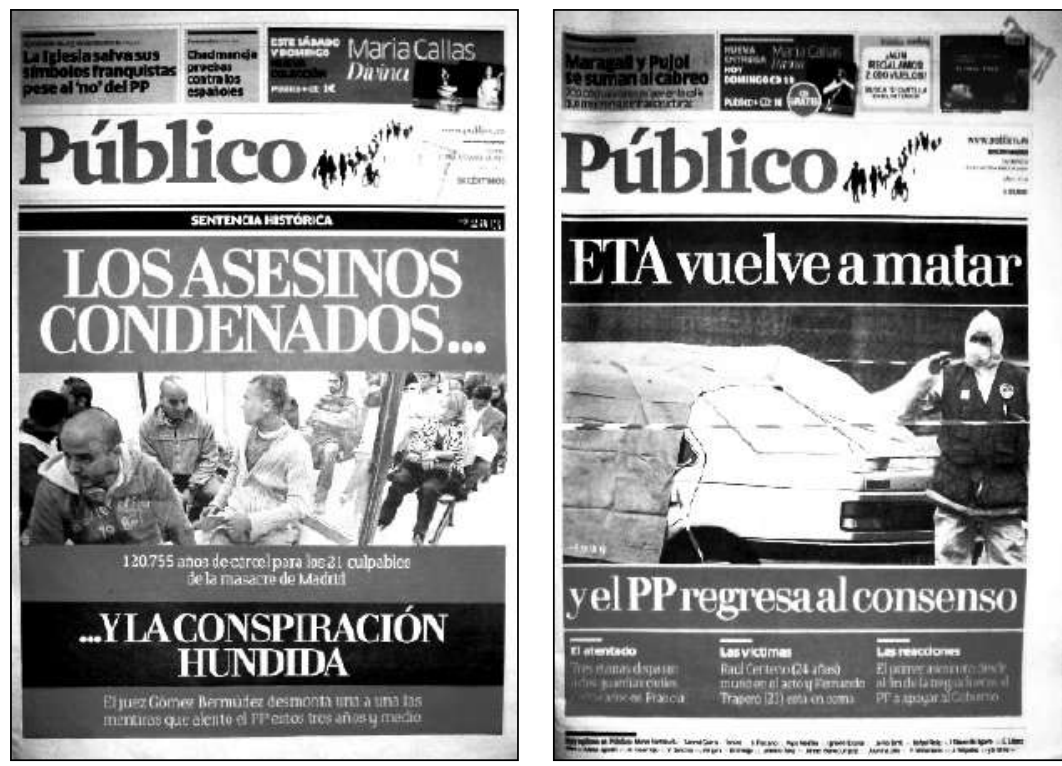

Fuente: Diario Público (1/XI/2007 y 2/XII/2007).

El empleo de la conjunción copulativa (“y”), que sirve para subrayar dos posiciones diferentes, también se observa en la figura 4, así como la gran ampliación del tercer bloque y la bipartición del titular principal. La imagen del coche (de los dos guardias civiles asesinados) separa la oración: sus dos segmentos están contenidos en recuadros de colores distintos.

Sin embargo, un mayor protagonismo adquirieron las imágenes en la primera página, muchas de las cuales poseyeron una naturaleza creativa, colorida y didáctica, propia de las infografías que suelen acompañar a las notas informativas y a los reportajes. Como se observa en la figura 5, la caja de un disco compacto se articula con el contenido noticioso: el debate en torno al papel de la Sociedad General de Autores y Editores (SGAE), un organismo acusado de lucrar con los ingresos millonarios que obtienen músicos y compositores. La superficie de la caja contiene el titular y los tres subtítulos que componen la denuncia. 
Figuras 5 y 6: Empleo de infografías en portadas.
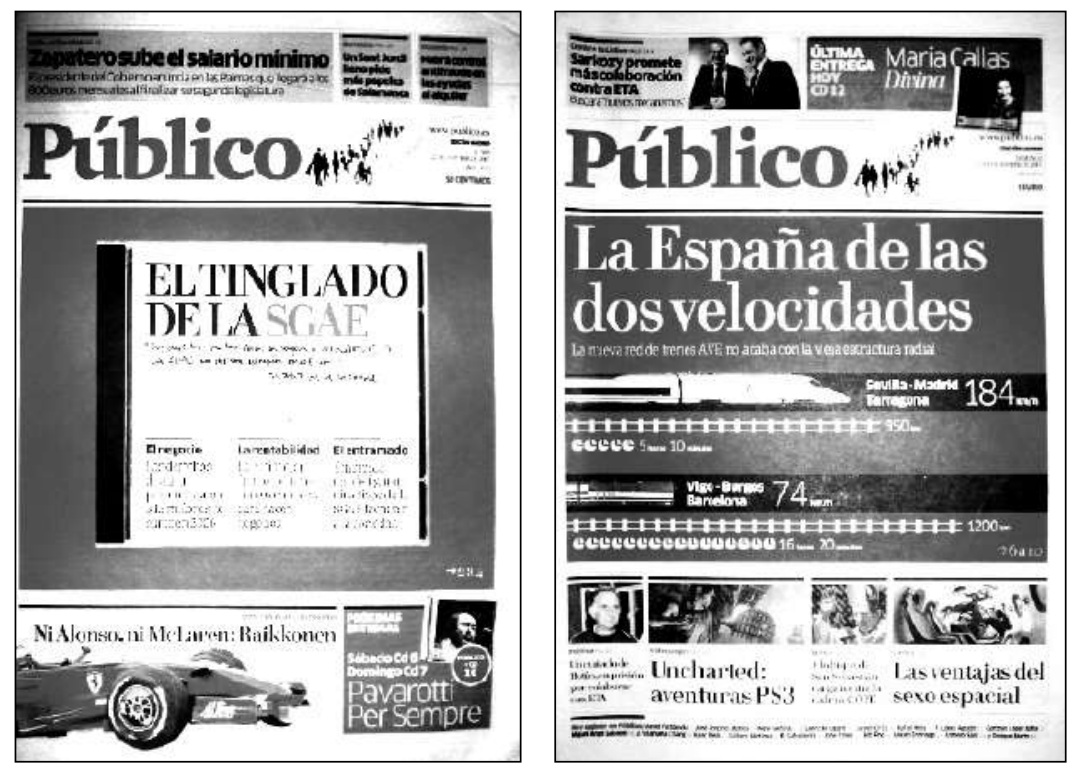

Fuente: Diario Público (22/X/2007 y 9/XII/2007).

Pese a los problemas que sufrió el sistema ferroviario de Barcelona (a finales del 2007) algunas portadas (figura 6) resaltaron las ventajas de la Alta Velocidad Española (AVE). Dentro del consabido recuadro de fondo rojo, se ilustró el ahorro de tiempo en la ruta Sevilla-Madrid-Tarragona ante la lentitud de la anterior red de trenes encarnada en la ruta Vigo-Burgos-Barcelona. Tal dicotomía se vuelve más diáfana con el empleo de dibujos y cifras de gran tamaño.

No hay duda que la temática predominante en este trimestre fue la campaña electoral: las críticas y ataques de los titulares de Público se enfilaron decisivamente contra el Partido Popular y sus principales líderes. Tal como se aprecia en la figura 7, Mariano Rajoy (en ese entonces candidato de la oposición) es caricaturizado como un personaje oportunista y chauvinista debido a la parafernalia utilizada por este personaje en un video "institucional" de YouTube (12/X/2007), similar a la utilizada en las apariciones oficiales del monarca en la televisión en Nochebuena.

El titular resalta la poca originalidad de la campaña del PP; si bien los paréntesis son pocos frecuentes en la primera página, su empleo, en este caso, tuvo una función irónica. Esto último fue reforzado con la imagen de Rajoy en YouTube (donde se ve el puntero del ratón sobre su rostro) y los fondos bicolores de la bandera española. 
Figuras 7 y 8: Portadas dirigidas contra líderes del PP.
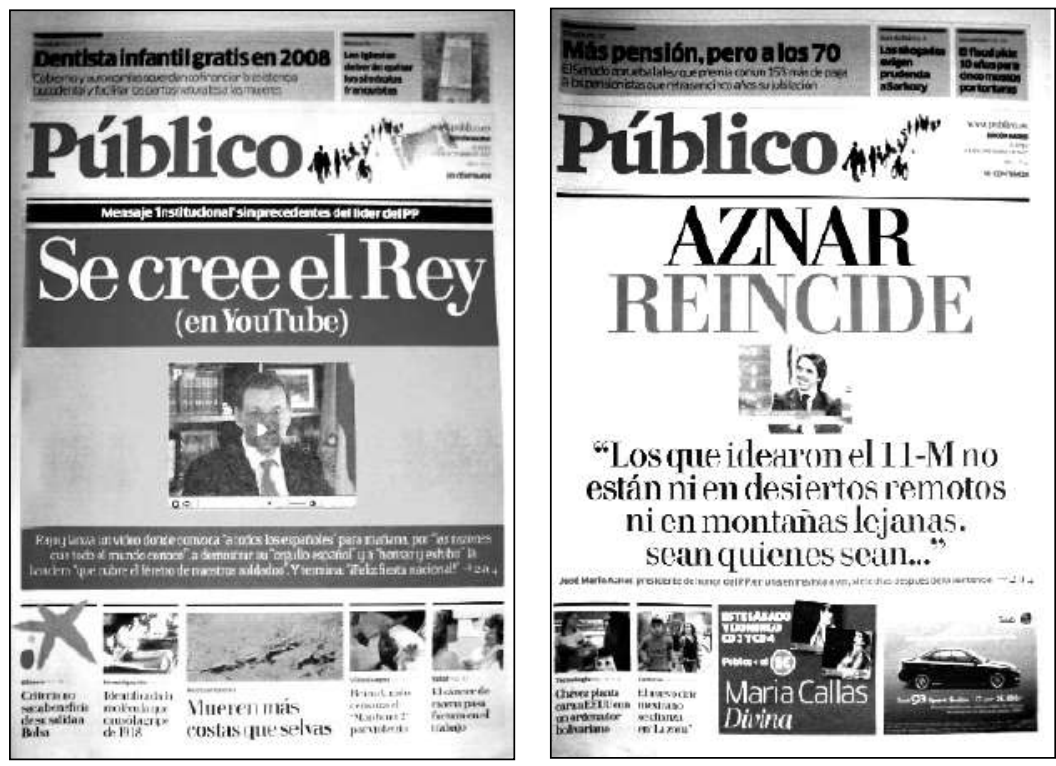

Fuente: Diario Público (11/X/2007 y 8/XI/2007).

En otra portada (figura 8) se recogen las impresiones "conspirativas" del ex presidente José María Aznar sobre la autoría de los atentados del 11-M. Con la finalidad de brindar mayor impacto a estas polémicas declaraciones, se evitó sobredimensionar el fotograma del mencionado político, así como los fondos rojos, característicos del diseño modular de esta publicación. La sencillez de los blancos no evitó el empleo de tipos en altas y un extenso subtítulo a cuatro líneas, que básicamente es una cita textual de Aznar.

\section{Segundo trimestre (enero - marzo 2008)}

Desde fines de enero de 2008, la portada de Público comenzó a adoptar el diseño "abrazadera", donde los titulares y textos secundarios rodean la noticia principal de la portada formando una "L invertida". El sentido horizontal se abandonaba, orientándose hacia una mayor verticalidad en la disposición de los elementos. Con la finalidad de acentuar el cambio de la pauta, se removió el bloque que aparecía encima de la cabecera, para convertirlo en una columna de gran longitud en el extremo derecho de la página. De esta manera, el rótulo del diario se posicionó en una zona superior donde adquirió mayor visibilidad e importancia. 
Figuras 9 y 10: Portadas bajo el esquema de la "L invertida".
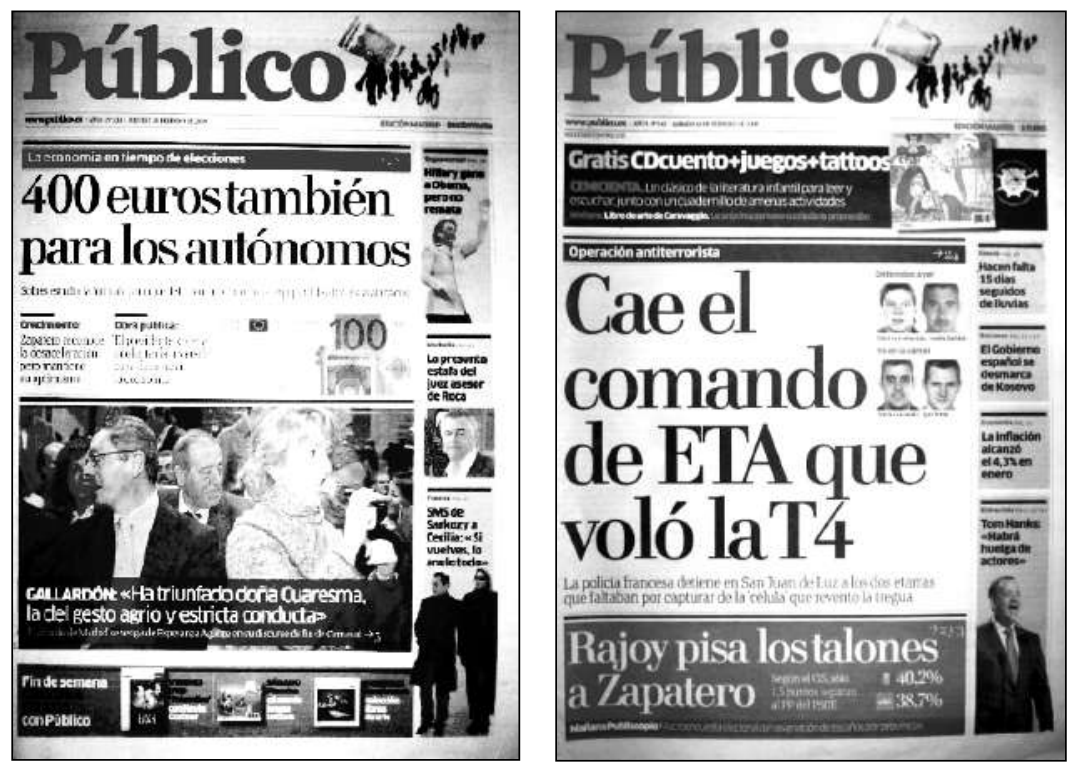

Fuente: Diario Público (7/II/2008 y 16/II/2008).

Como se puede observar en la figura 9, el bloque inferior de noticias y otras zonas publicitarias fueron empequeñecidos con la finalidad de brindar más preeminencia al bloque principal. En ambas portadas se evidencia un mayor empleo de cintillos, colores vivos y una cantidad ingente de fotografías silueteadas en el extremo derecho. En la figura 10 podría afirmarse que la noticia principal está cercada por una "C" y no por una "L", gracias a un bloque de promoción, emplazado debajo de la cabecera. Dicho espacio, dominado por un fondo negro, recibió un peculiar tratamiento informativo, ya que contó con titular en negras y diferentes colores en los tipos, así como un extenso subtítulo y una fotografía.

La orientación vertical del diseño de Público fue contemporánea a cambios drásticos en la pauta, a fin de aumentar las cotas dramáticas y expresivas. Un atentado de ETA (en los días previos a las elecciones del 9 de marzo) motivó el empleo de grandes fotografías que ocuparon toda la superficie de la portada, incluso la dedicada a la cabecera, que siempre se había mantenido sin fondo.

La indignación por el asesinato del ex concejal socialista Isaías Carrasco en Mondragón (País Vasco) fue crudamente ilustrado con la ráfaga de las balas asesinas (figura 11) que impactaron en su automóvil. Un día después apareció el rostro de Sandra Carrasco, hija de la víctima, durante el funeral (figura 12). Los titulares recurrieron al tono apelativo y enérgico, exigiendo no sólo la condena a ETA, sino impulsar el voto ciudadano, que se erigiría como una herramienta cívica contra la violencia. 
Figuras 11 y 12: Portadas con grandes fotografías.
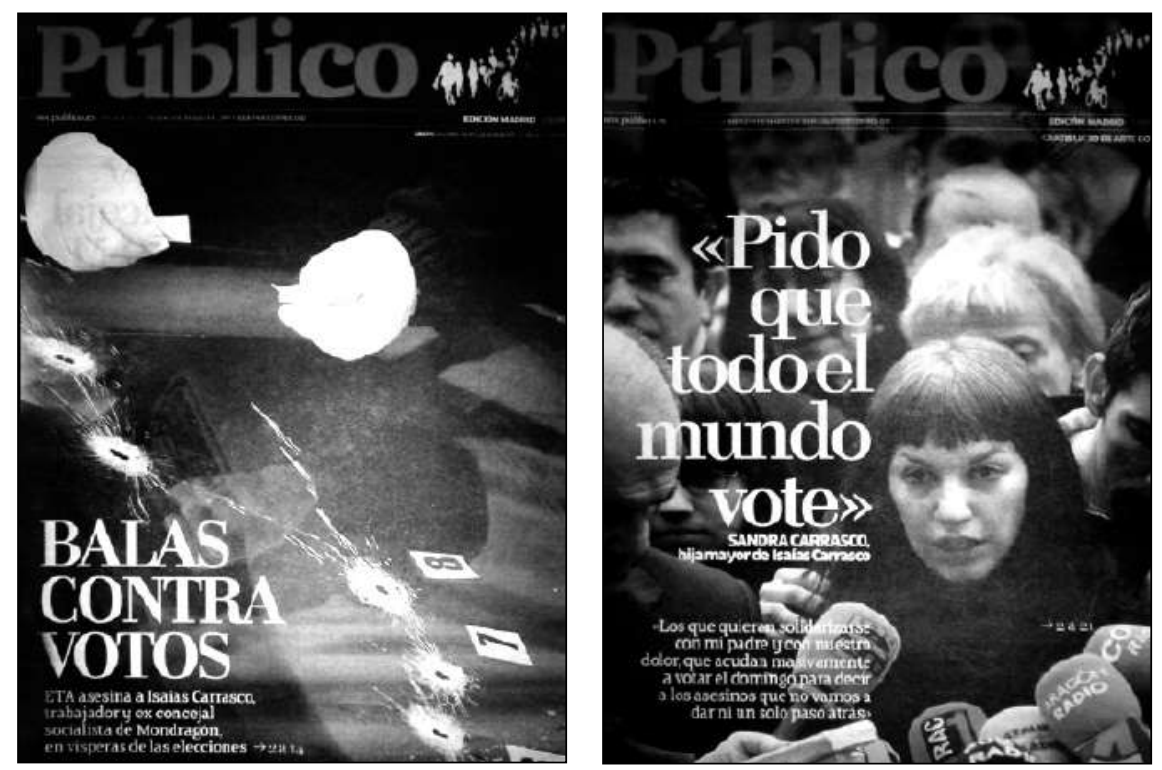

Fuente: Diario Público (8/III/2008 y 9/III/2008).

El recurso de fragmentar el titular principal fue empleado para resaltar irónicamente las tensas relaciones surgidas entre los dirigentes del Partido Popular. En la figura 13 aparecen tres líderes del mencionado partido (dos de ellos silueteados para no ocultar el rótulo). Los tres segmentos del titular aparecen divididos por el uso del color ("Rajoy cede") y pese a su brevedad retratarían la impulsividad de la entonces presidenta de la Comunidad de Madrid, la debilidad del alcalde de la capital y el poco liderazgo de Rajoy para poner orden y consenso dentro de su propio partido.

En la figura 14, la "L invertida" rodeó dos fotografías con sus respectivos títulos: la primera imagen mostró la reunión de confraternidad entre los principales miembros del Partido Popular (Aguirre y Rajoy en primer plano, aunque a espaldas de la cámara) y la segunda demostró el ostracismo y la soledad que sufriría Ruiz-Gallardón en un aparcamiento de automóviles, el cual, para variar, estaba vacío. Los puntos suspensivos sugieren continuidad para una frase llena de sarcasmo. 
Figuras 13 y 14: Portadas con "multi-titulares".
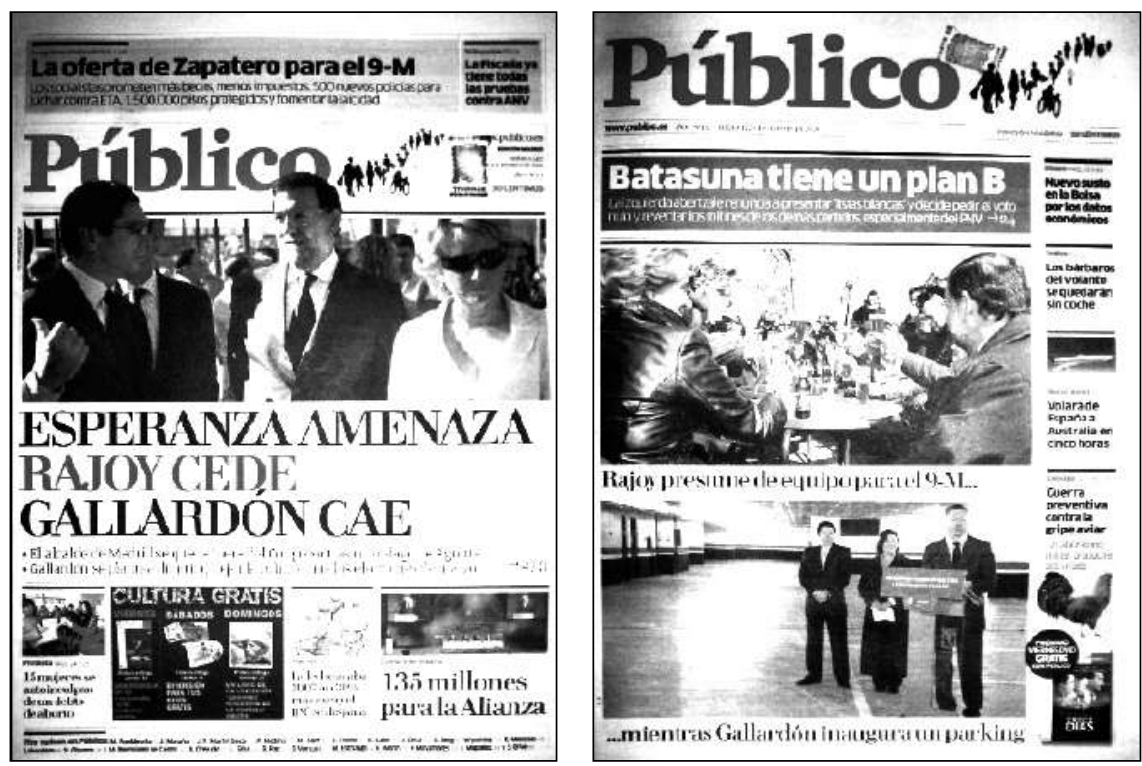

Fuente: Diario Público (16/I/2008 y 6/II/2008).

El didactismo de las portadas “infográficas" se evidenció con mayor claridad en la figura 15, enmarcada en la campaña mediática contra los accidentes automovilístico de fin de año. Con un fondo verde, el bloque principal mostró las cinco razones fundamentales que redujeron la mortalidad en las carreteras. Los iconos de prevención y los signos matemáticos apoyaron la elementalidad y claridad del mensaje. Con menos afán divulgativo, una edición post-electoral (figura 16) se colocó una letra “Z”, la cual se había convertido en el símbolo principal de la campaña del PSOE. El titular cita la localidad donde el flamante presidente reelecto, Rodríguez-Zapatero, solucionaría un complejo rompecabezas: la composición de su gabinete ministerial. 
Figuras 15 y 16: Portadas con infografías.
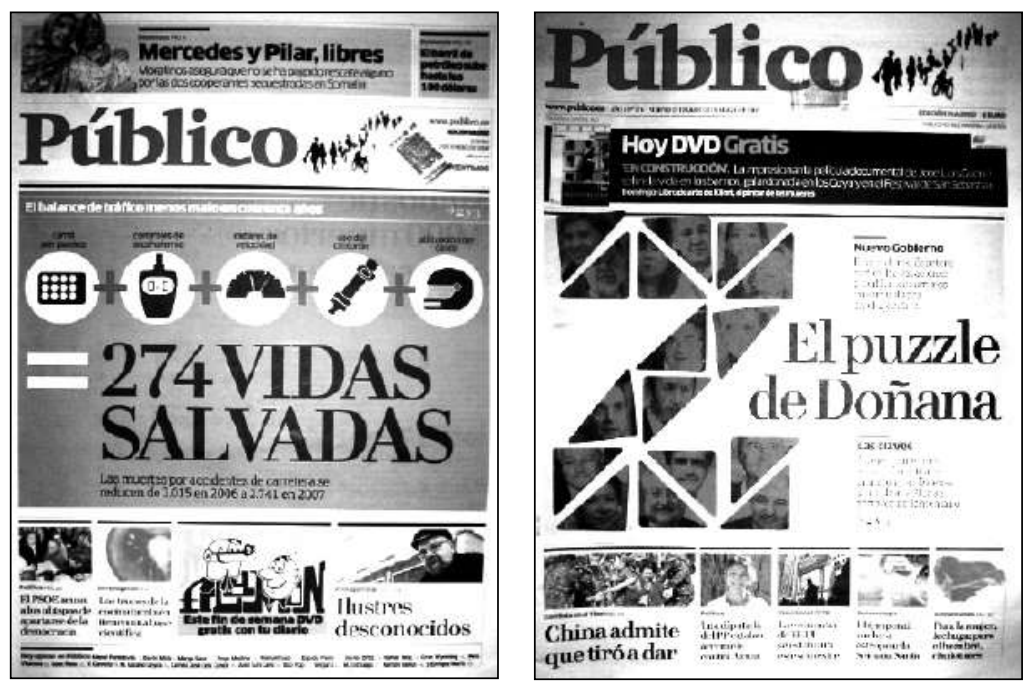

Fuente: Diario Público (3/I/2008 y 21/III/2008).

A pesar de la poca diferencia, en cifras porcentuales, entre los dos principales candidatos en marzo de 2008 (4.4\%), Público no dudó en afirmar que Rajoy era incapaz de "cerrar la brecha" y superar a Rodríguez-Zapatero. Por ese motivo, se dejaría asesorar por la "Vieja Guardia" del PP, encarnada en José María Aznar, quien sostiene uno de los brazos de Rajoy en la foto principal (figura 17) y se lanzaría desesperadamente a la calumnia y al ataque personal contra el líder socialista y movilizar a los votantes indecisos.

Figuras 17 y 18: Portadas durante campaña electoral.
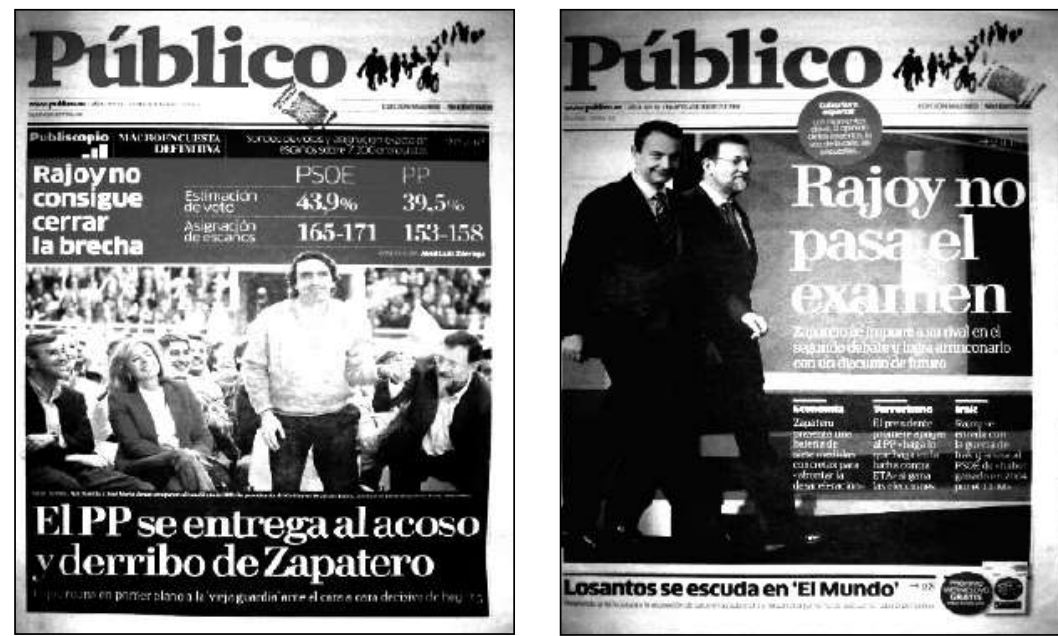

Fuente: Diario Público (3/III/2008 y 4/III/2008). 
La cobertura a los debates televisados acaparó la atención de este diario. En la figura 18, se sostiene que Rajoy no pudo convencer a los electores con su discurso desplegado durante el segundo debate. Esta aura de derrota y fracaso ("Rajoy no pasa el examen") es apoyado visualmente al colocarse la figura de un sonriente Rodríguez-Zapatero ante un semblante dubitativo del líder del PP.

Público plasmó la victoria del PSOE con una explosión de jovialidad, apostando por un fuerte fondo rojizo en su bloque principal (figura 19), ilustrando nuevamente la " $Z$ " con signos de admiración. Diseñada con trazos bruscos, vigorosos y casi juveniles, como un tosco graffiti, la presencia de esta letra opacó el resto de noticias electorales: el segundo fracaso consecutivo de la derecha española, el apoyo vital de los socialistas catalanes y de los votantes de Izquierda Unida, en desmedro de su propio partido.

Las portadas post-electorales sobre el Partido Popular buscaron ahondar el desconcierto y falta de liderazgo que habría estado experimentando el Partido Popular. Luego de la debacle en las urnas, se daba por descontada la renuncia de Rajoy a la presidencia del PP (figura 20), para encontrarse contradicha prontamente al día siguiente ${ }^{5}$.

Figuras 19 y 20: Portadas poselectorales.
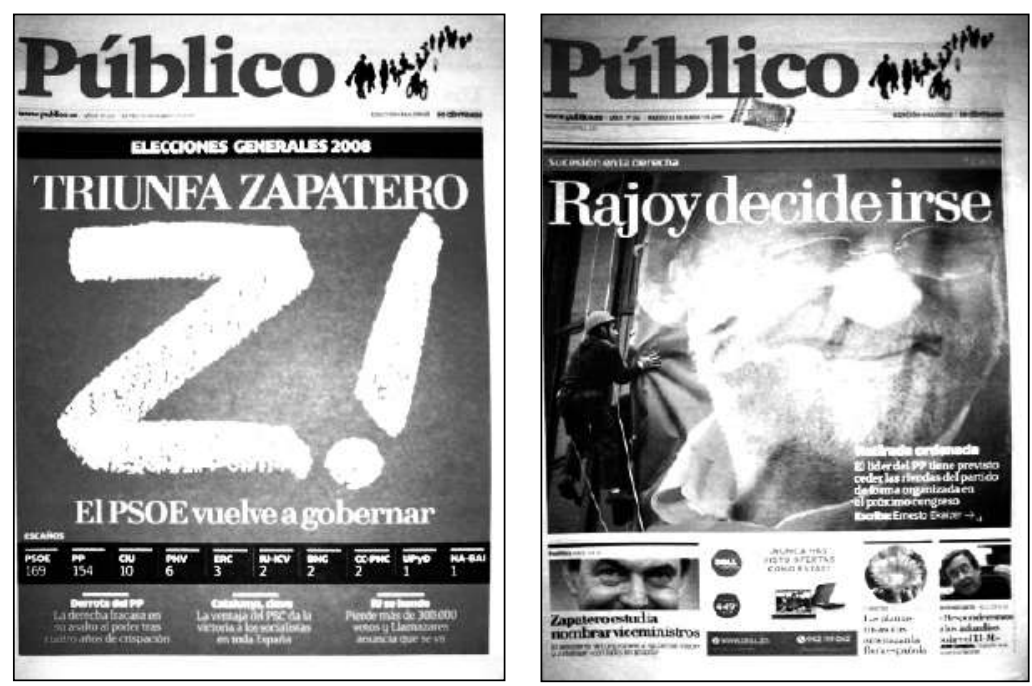

Fuente: Diario Público (10/III/2008 y 11/III/2008).

5. El titular principal de dicha edición fue "Rajoy quiere repetir" (12/III/2008), donde aparece el dirigente gallego recibiendo un abrazo de Esperanza Aguirre, a modo de consuelo. Tal imagen resultaría irónica, ya que muchos medios insistieron en las inocultables ambiciones de la entonces presidenta de la Comunidad de Madrid en ser la sucesora de Rajoy en el PP, con la venia de Aznar. 


\section{Tercer trimestre (abril - junio 2008)}

El diseño "abrazadera" conservó sus principales características en este período: cabecera en la parte superior de la página, un bloque informativo en el borde derecho y otro más ubicado debajo de la cabecera (figura 21) o del bloque principal.

Figuras 21 y 22: Portadas con variaciones del esquema "L invertida".
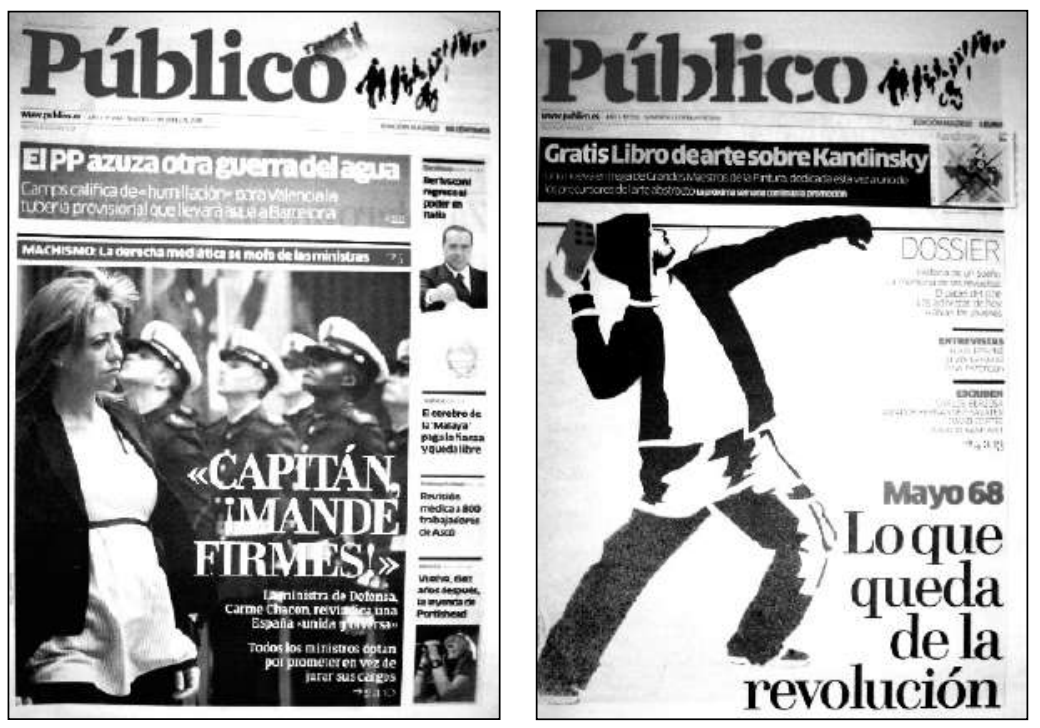

Fuente: Diario Público (15/IV/2008 y 18/V/2008).

Sin embargo, la "L invertida" cedió ante la simplificación, formándose bloques principales de gran altura y anchura (figura 22). En la portada conmemorativa del "Mayo Francés", la cabecera, el bloque de promociones y la noticia principal (conformada por una ilustración de Álvaro Valiño y textos al margen derecho que anunciaba un dossier especial) mostraron la tripartición de la pauta.

El empleo de vastos antetítulos y subtítulos en la noticia alcanzaron su mayor expresión en ediciones dedicadas al ocio (figura 23) y a la coyuntura política (figura 24). Ambas portadas estuvieron saturadas de interminables líneas que buscaron resaltar la trascendencia del titular principal. Al emplear tipos de distintos colores (negro con rojo, blanco con amarillo) se saturó el campo visual del lector.

Resulta sorprendente que una publicación periodística, de circulación nacional, dedicase su primera página a un videojuego como Grand Theft Auto 4, caracterizado por su violencia y difusión de actividades transgresoras (figura 23), si bien dicha temática suele estar presente 
en revistas juveniles o de informática ${ }^{6}$. En todo caso, las cincuenta palabras del subtítulo, que acompañan al héroe ficticio del GTA 4 (Niko Bellic) no superaron las más de noventa reunidas en los dos antetítulos de la edición dedicada al PP (figura 24).

Figuras 23 y 24: Portadas con extensos antetítulos y subtítulos.
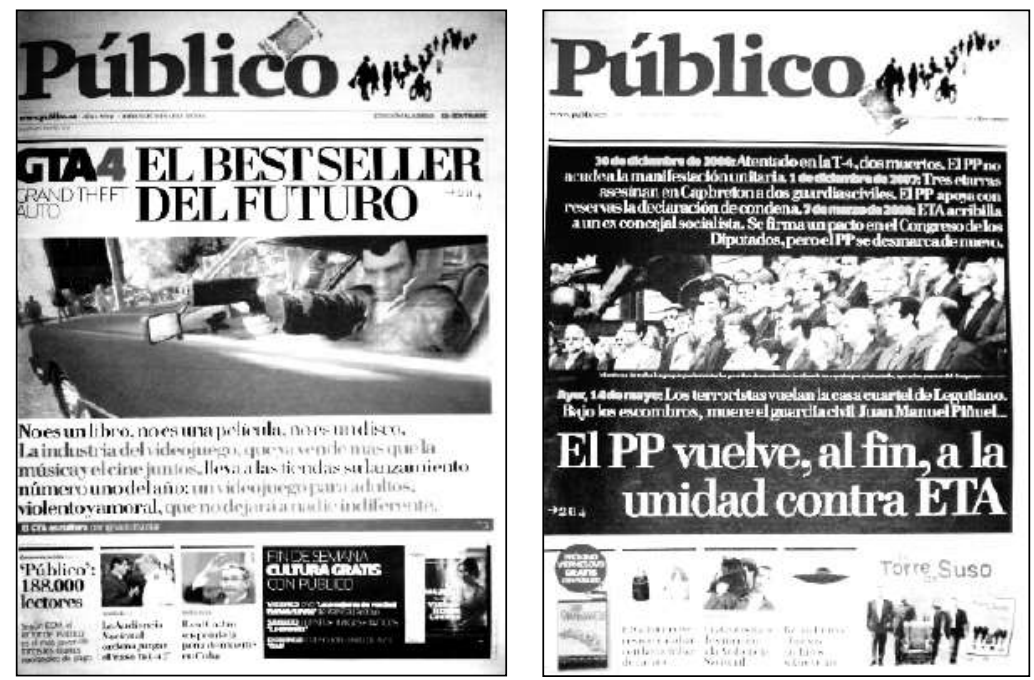

Fuente: Diario Público (30/IV/2008 y 15/V/2008).

Equipados de ladillos amarillos, los mencionados antetítulos fueron desarrollados como una breve nota informativa, relatando la indiferencia y el silencio inicial del PP frente a los atentados terroristas de ETA. Sin embargo, el asesinato del guardia civil, Juan Manuel Piñuel, condensado en el segundo antetítulo, significó el cambio de actitud de la oposición, que fortalecería la unidad política frente a la amenaza etarra.

Otra de las sorpresas temáticas de Público fue la presencia superlativa de la selección española de fútbol, que obtuvo la Copa Europea de Naciones (2008). La euforia por los éxitos y victorias del combinado español provocaron cambios drásticos en la portada, sobredimensionándola y obligándola a fundirse con la contracara. Este estilo grandilocuente y poster fue deudor de los tabloides deportivos del mercado ( $A s$, Marca), los cuales recurrieron a dicho recurso con la finalidad de poder apreciar, con detalle, la "grandeza" de los campeones.

6. El lanzamiento al mercado del cartucho más esperado de la temporada, Grand Theft Auto 4, no sólo recibió una amplia cobertura noticiosa en la portada, sino en varias páginas interiores. En su columna titulada "El GTA es cultura" (30/IV/2008, p. 4), el propio director de Público, Ignacio Escolar saludó el lanzamiento del videojuego y justificó su valor cultural: "Es una ficción, una novela negra. Y, como tal, no tiene por qué ser políticamente correcta. No es apto para menores de 18 años -lo pone bien claro en su etiquetado- como tampoco lo es una película de Tarantino o Scorsese. La confusión viene del nombre: videojuego. El juego se relaciona con la infancia y en el nombre de los niños [...] Pero los videojuegos no son sólo cosa de niños: la edad media de los que jugamos cada vez es más elevada y hoy ronda los $25 \%$. 
Figuras 25 y 26: Unión de la primera página con la contraportada.
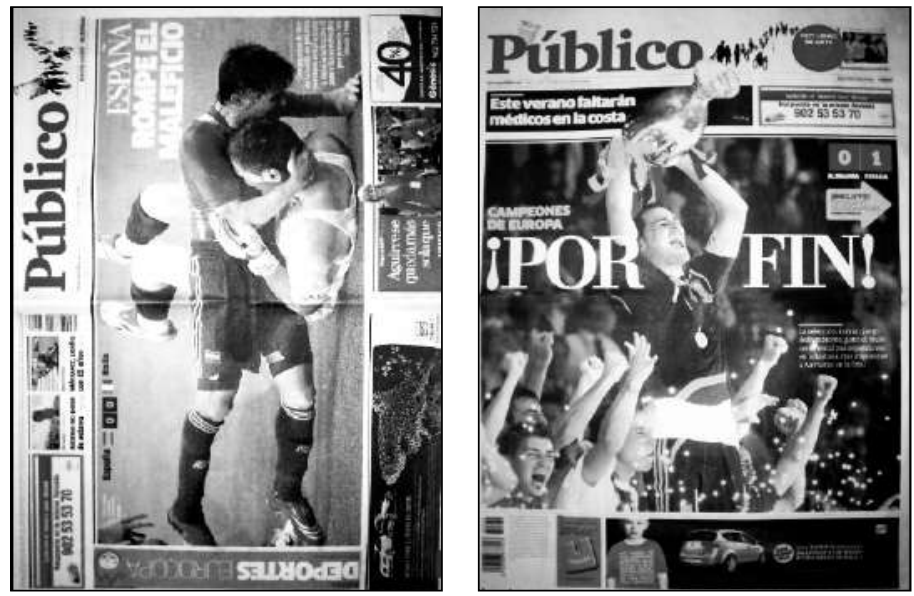

Fuente: Diario Público (23/VI/2008 y 30/VI/2008).

Si bien en la figura 25 se aprecia un sentido horizontal, la fotografía principal fusionó ambas páginas externas, con la imagen de dos jugadores españoles abrazados eufóricamente, luego de superar a la selección italiana por penales y pasar a las semifinales. Dispuesto de forma abierta y vertical, se contempló la pauta de tres módulos: cabecera, noticia principal y bloque inferior informativo, todos ellos separados por corondeles y blancos.

La cobertura de la conquista del título (figura 26) dejó de lado las noticias políticas o de naturaleza extra-deportiva en la portada: sólo se pudieron identificar espacios dedicados a la promoción y a la publicidad. La única excepción fue un pequeño recuadro negro, casi oculto por la copa alzada por el exultante capitán de la selección española. En dicha zona encontramos una vaga noticia acerca de las playas veraniegas, sin profundidad ni foto que lo acompañase.

El empleo de grandes imágenes fue paralelo a su exacerbada multiplicación, aunque en pequeñas dimensiones, en las denominadas "portadas multifotos". En la figura 27, se observa una serie de fotografías silueteadas de las nueve ministras del gabinete de Rodríguez-Zapatero ${ }^{7}$. Si bien todas ellas aparecen en un mismo plano, no reciben el mismo tamaño. Como vicepresidencia de Gobierno, María Teresa Fernández de la Vega adquirió la mayor dimensión, seguida de Bibiana Aído, del Ministerio de la Igualdad. Una estática Beatriz Corredor (ministra de Vivienda) contrastó con el andar dinámico de Carme

7. El titular de esta edición se configuró como una respuesta a las declaraciones del entonces presidente italiano Silvio Berlusconi, quien tildó de "gobierno rosa" al equipo político de Rodríguez-Zapatero. El desafortunado aforismo generó una crítica macroestructural a la sociedad italiana, a cargo del columnista Manuel Saco (17/ IV/2008, p. 9): "Pobre Italia. En el Vaticano reina un ex nazi que llegó al papado gracias a la enorme influencia obtenida como director del organismo heredero de la Inquisición [...] Y en el palacio del Quirinal, y por mayoría absoluta gracias a los votos del partido fascista de la Liga Norte, ocupa el sillón de la presidencia del gobierno italiano un patético ex boy que lucha contra los estragos del tiempo a golpe de botox, machista irredento". 
Chacón, responsable de la cartera de Defensa. El resto del gabinete apareció alejado y empequeñecido, sobre todo Magdalena Álvarez, quien retuvo la cantera de Fomento.

Figuras 27 y 28: Portadas "multi-fotos".
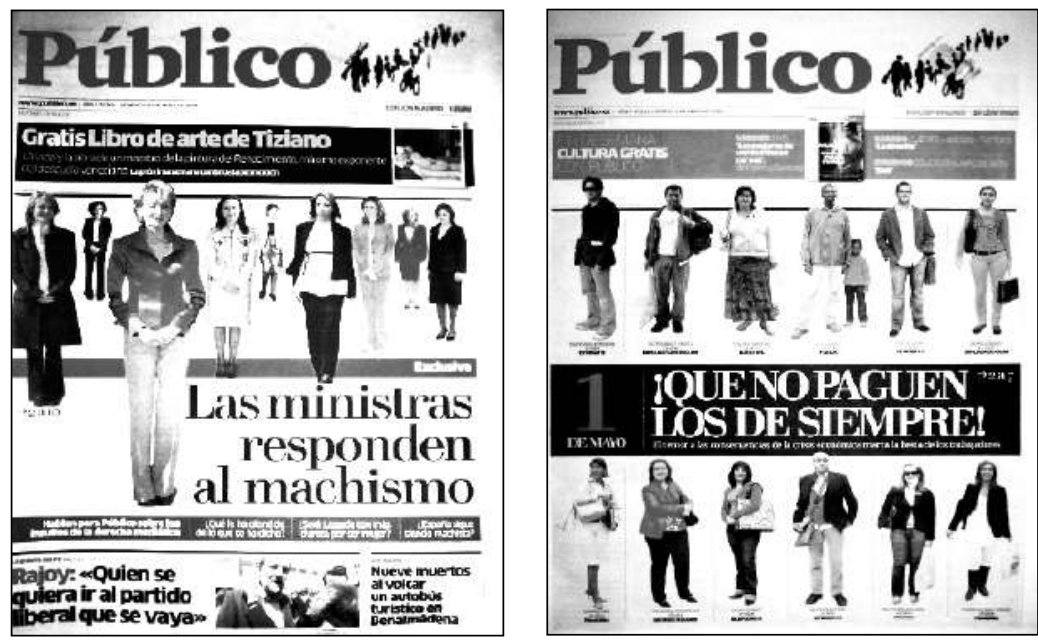

Fuente: Diario Público (20/IV/2008 y 1/V/2008).

Una disposición más ordenada del material fotográfico la encontramos en la edición dedicada al día del trabajo (figura 28). El titular, contenido en un recuadro negro, separa los dos bloques de fotografías, que reunieron en total trece imágenes de personas. Divididas por finos corondeles puntuados, cada fotografía representa los diferentes estamentos de la clase media española, expuesta a la crisis económica: jóvenes estudiantes, graduados sin empleo, emigrantes cabezas de familia, profesionales, empíricos, entre otros.

La recurrencia de caricaturas parodió in extremis a los principales dirigentes del PP. El contenido gráfico que expuso una aparente crisis interna en dicho partido (figura 29) abre un profundo cuestionamiento acerca de la naturaleza "crítica" e "investigadora" de Público. La abundancia de gráficos y germanías, de dudoso rigor periodístico, son bastante comunes en las portadas de la prensa sensacionalista y "farandulera".

Con un espíritu socarrón y cáustico, la caricatura de Manel Fontdevila retrató a varios dirigentes del PP mediante los diferentes pasos de una canción entonces de moda ${ }^{8}$. Dispuesto en cuatro pasos, la secuencia se inicia con María San Gil, "despidiéndose" de su cargo en el País Vasco; le sucede Ángel Acebes, quien continúa "negando" la autoría del 11-M a los terroristas islámicos; luego encontramos a Rajoy "aterrorizado" ante el próximo congreso del PP; y cierra un cibernético Aznar, quien parece tener "voz y voto" dentro del partido.

8 El denominado chiki-chiki, sencillo del cantautor "Chikilicuatre", quien representó a España en la edición de 2008 del Festival de la Canción de Eurovisión. 
En otra portada, se retrata a Federico Jiménez Losantos y a Alberto Ruiz-Gallardón (figura 30) como efigies siniestras y fantasmagóricas, los cuales aparecen perdidos dentro de un fondo oscuro. Al lado izquierdo se muestra una casi imperceptible nota informativa de Ángeles Vázquez, donde se narra el inicio del proceso judicial contra el locutor de la COPE, por el delito de injuriar al entonces alcalde de Madrid.

Figuras 29 y 30: Portadas con caricaturas.
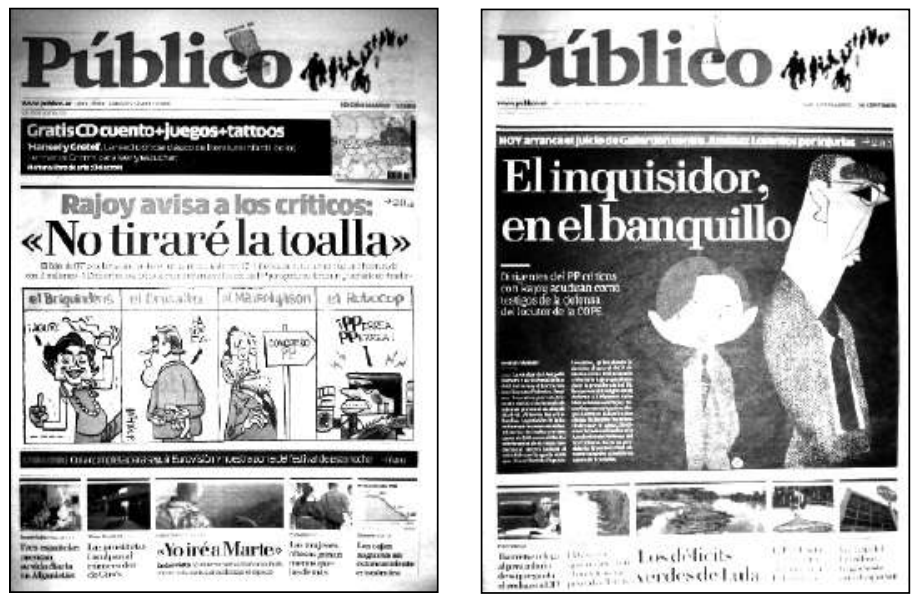

Fuente: Diario Público (24/IV/2008 y 28/V/2008).

Tras la derrota electoral, muchas de las portadas de Público se enfilaron contra Rajoy, siempre con un tono irónico y alegorías gráficas. En la figura 31, el aparente aislamiento del líder del Partido Popular fue equiparado al de un celular "apagado o sin cobertura".

Figuras 31 y 32: Portadas dedicadas a Mariano Rajoy.
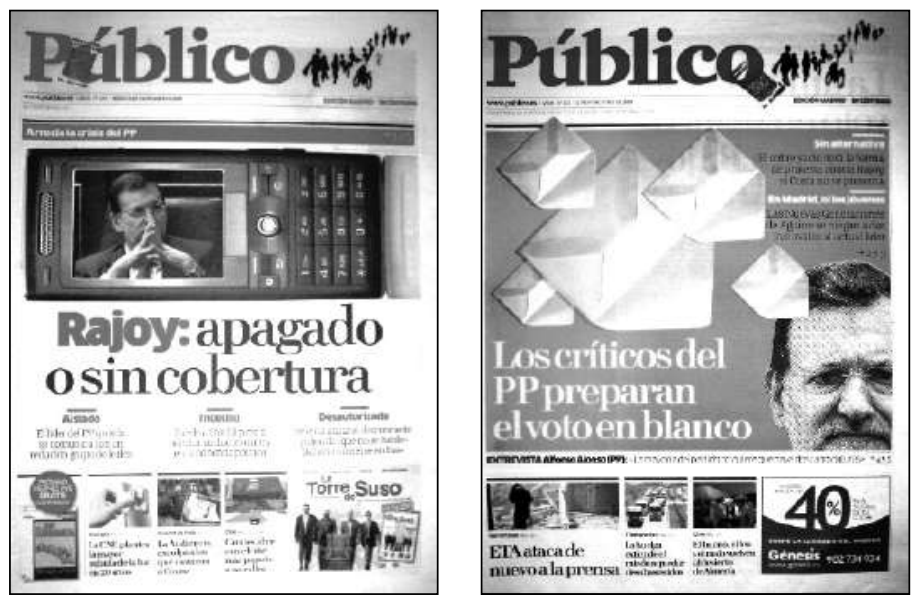

Fuente: Diario Público (14/IV/2008 y 9/VI/2008). 
Con un esquema similar, en otra portada (figura 32) se intentó reflejar la posición solitaria del dirigente gallego ante el nuevo Congreso del PP: la única forma de evitar su reelección sería el voto en blanco. Ello explicaría los sobres vacíos, en forma de saetas, dirigidos directamente contra el actual presidente de Gobierno.

La otra tendencia del diseño de Público fue el expresionismo obtenido de los fotomontajes. En la figura 33 este recurso gráfico ilustró la supuesta "bicefalia ideológica" entre la apertura hacia el centro, que intentaba ensayar Rajoy, y la postura "atávica" de Aznar hacia posiciones más conservadoras. De esta manera, las "dos caras de PP" conviven, pero sin estar amalgamadas dentro de un pensamiento común y consensuado. La fractura (que emula el corte de una fruta) parecería beneficiar al ex presidente Aznar, cuya figura aparece más elevada y serena que la otra faz de la izquierda.

Figuras 33 y 34: Portadas dedicadas al Partido Popular.
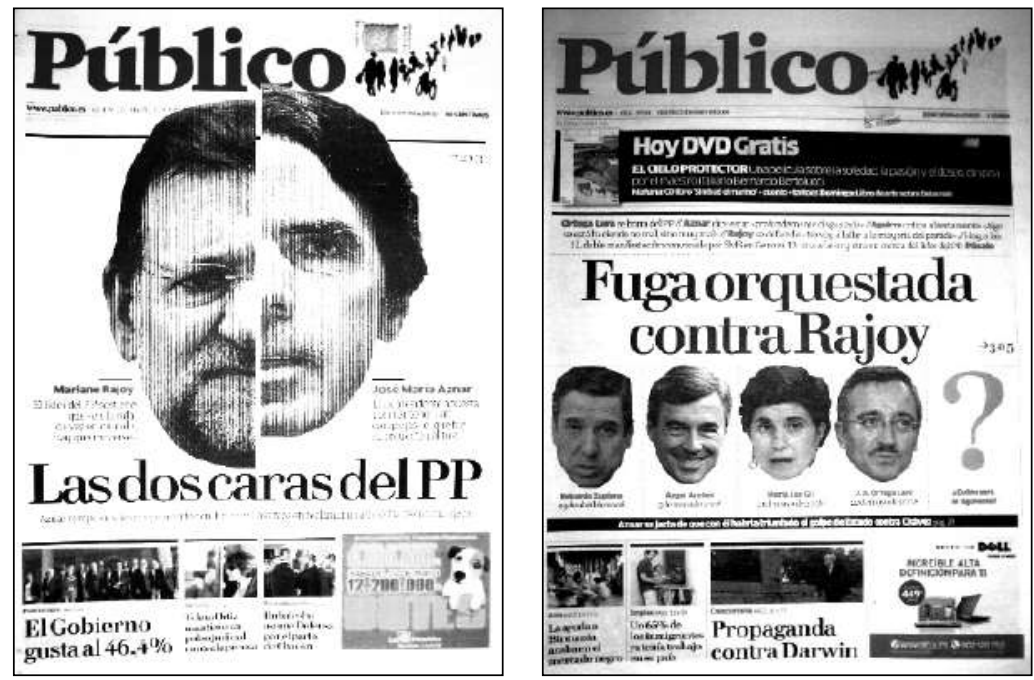

Fuente: Diario Público (20/V/2008 y 23/V/2008).

La aparente "diáspora" de las principales figuras del PP, luego de los resultados electorales, fue aprovechada por Público para lanzar varias teorías que especulaban la renuncia de Mariano Rajoy a la presidencia del Partido Popular y la asunción de nuevos protagonistas como Esperanza Aguirre o el propio Aznar. Mediante retratos ovalados (figura 34), se apreció la retahíla de renuncias (Zaplana, Acebes, San Gil y Rodríguez Lara, esta última producida el día anterior a la publicación) y la sospecha de una "fuga orquestada" por aquellos interesados en vetar a Rajoy para las elecciones del 2012.

El aspecto irónico de la portada residió en el carácter secuencial de las fotografías, que comulgó con la lógica "conspirativa" del titular y de su extenso antetítulo, dedicado a recoger citas aisladas de los principales líderes del PP. Divididas por finos corondeles punteados, estas fotos silueteadas ceden el punto de atracción al intrigante signo de interrogación. 
Los tonos grises de las fotografías de ambas portadas resumirían la naturaleza "agotada" y "expirada" de dichos personajes políticos.

\section{Reflexiones finales}

Dentro de la clasificación de las portadas periodísticas, Público respondió a diversas fórmulas expresivas, sin encasillarse en una sola. Los rasgos "arrevistados" y vistosos de sus portadas, los titulares de tono "semiserio" y la ingente cantidad de elementos gráficos lo identificaron como un "tabloide-cartel", dentro del modelo "popular-sensacionalista". Este esquema es bastante común en el continente americano (Newsday, New York Post), donde el formato tabloide es sinónimo de espectacularidad visual y textos provocativos, pero poco profundos.

No obstante, la cobertura noticiosa de este diario no respondió estrictamente a razones de "interés humano". Pese a la calidez e informalidad de sus primeras planas, Público conservó cierto orden formal en sus elementos textuales y gráficos. Y lo más importante: sus aristas sensacionalistas no estuvieron centradas en la farándula o en personajes estrafalarios, sino en el acontecer político, temática predominante en sus portadas, aunque teñida de tendenciosidad y polémica.

Además de exhibir calidezy desenfado, las portadas se rigieron por una presentación excesivamente legible y de fácil comprensión. Su diseño modular estuvo compuesto por tres o cuatro bloques rectangulares, todos ellos coloridos y con ingentes recursos gráficos. Sin embargo, uno sobresalía del resto: la noticia del día se ubicaba en el centro de la página, adquiriendo grandes dimensiones. Este diseño elemental alternó algunas veces con el estilo "abrazadera", así como la fusión de la portada y la contra para informar sobre acontecimientos importantes.

Dentro de este esquematismo, las portadas de Público tuvieron la cualidad de albergar elementos infográficos. De naturaleza didáctica y alegórica, se erigieron como un recurso creativo y poco convencional, en el cual las fotografías y recursos gráficos abandonaron su función decorativa y se convirtieron en elementos intrínsecos de la noticia. Además de articular el contenido informativo, añadieron cierto tono distendido y humorístico en la primera página. Los infográficos no fueron los únicos protagonistas de las portadas. Los diseñadores no se contentaron en colocar un gran número de fotografías silueteadas (las portadas "multifotos" llegaron a superar la docena) sino en echar mano a la gracia corrosiva de las caricaturas.

La incidencia de germanías y coloquialismos, sobre todo en las portadas y titulares, aumentó el grado de hilaridad y desenfado a esta publicación, que pretendió erigirse como una fuente de información seria y responsable. Sin embargo, el buen humor y la comicidad degeneraron en agrios sarcasmos y crueles parodias al informar acerca del "conservadurismo" político. Miembros del Partido Popular (Mariano Rajoy, Esperanza Aguirre, Alberto Ruiz-Gallardón, José María Aznar, entre otros) fueron objeto de ataques a su labor. El blanco preferido fue el dirigente gallego, quien recibió innumerables calificativos, citándose su incompetencia, torpeza, débil liderazgo, actitud xenófoba, entre otros. 


\section{Fuentes consultadas}

Armentia Vizuete, J. y Caminos Marcet, J.

_(2002). Fundamentos de periodismo impreso. Barcelona: Ariel.

_(1998). La información: redacción y estructuras. Bilbao: Universidad del País Vasco.

Armentia, J.; Elexgaray, J. y Pérez, J. (1999). Diseño y periodismo electrónico. Guipúzcoa: Universidad del País Vasco.

Armentia Vizuete, J. y otros (2000). El diario digital. Análisis de los contenidos textuales, aspectos formales y publicitarios. Barcelona: Bosch.

Bezunartea, O.; Martínez, F. y Del Hoyo, M. (1998). 21 lecciones de reporterismo. Guipúzcoa: Servicio Editorial de la Universidad del País Vasco.

Canga, J. (1994). El diseño periodístico en la prensa diaria. Normas básicas. Barcelona: Bosch Comunicación.

Canga, J. y otros (2000). Diarios digitales. Apuntes sobre un nuevo medio. Bilbao: Universidad del País Vasco.

Cantavella, J. (2012). La columna periodística. Presencia viva en la prensa hispanoperuana y anglosajona. Lima: Universidad de San Martín de Porres.

\section{Cantavella, J. y Serrano, J. (coords.)}

_(2004). Redacción para periodistas: informar e interpretar. Barcelona: Ariel. _(2007). Redacción para periodistas: opinar y argumentar. Madrid: Universitas.

Casasús, J. y Núñez Ladevéze, L. (1991). Estilos y géneros periodísticos. Barcelona: Ariel.

Charaudeau, P. (2003). El discurso de la información. La construcción del espejo social. Barcelona: Gedisa.

Escolar, I. (2007, septiembre 4). "Todo lo que siempre quiso saber sobre "Público". Extraída el 24/XII/2013 desde http://www.escolar.net/MT/archives/2007/09/todo-lo-quesiempre-quiso-saber-sobre-publico.html

Galdón, G. (2001). Desinformación. Método, aspectos y soluciones. Pamplona: Universidad de Navarra.

García, M. (1981). Diseño y remodelación de periódicos. Pamplona: Universidad de Navarra.

Gomis, L. (1987). El medio media. La función política de la prensa. Barcelona: Mitre. 
Herrero, C. (1996). Periodismo político y persuasión. Madrid: Actas.

López García, A. (1996). Escritura e información. La estructura del lenguaje periodístico. Madrid: Cátedra.

Martín Aguado, J. (1991). Proyecto y diseño de un diario. Madrid: Ciencia.

Martín Aguado, J. y Armentia, J. (1995). Tecnología de la información escrita. Madrid: Síntesis.

Público, diario.

_(2007, septiembre 26). Suplemento especial "Hoy nace tu diario".

_(2008, septiembre 26). Suplemento especial "Primer Aniversario". 